\title{
Yoğun bakım ünitemizdeki intoksikasyon olgularının geriye dönük incelenmesi
}

\author{
Tolga Totoz ${ }^{1}$, Hacer Şebnem Türk², Pınar Sayın², Surhan Çınar³, Çiğdem Yıldırım², Sibel Oba²
}

\begin{abstract}
ÖZET:
Yoğun bakım ünitemizdeki intoksikasyon olgularının geriye dönük incelenmesi Amaç: Intoksikasyonlar intihar amacıyla, kazayla ya da madde bağımlıı̆̆ gibi sebeplerle karşımıza çıkmaktadır. Bu çalışmada yoğun bakım ünitemizde üç yıl süresince takip ve tedavi edilen inoksikasyon olgularını incelemeyi amaçladık.

Gereç ve Yöntem: 2007- 2009 tarihleri arasında yoğun bakım ünitemizde intoksikasyon nedeniyle takip edilen 66 olgunun geriye dönük demografik verileri, etken maddeler, yatış süreleri ve mekanik ventilasyon intiyaçları incelendi.

Bulgular: Olguların 43'ü kadın, 23'ü erkek idi. Yaş ortalaması 24,92 $\pm 10,26$ olup 11 tanesi 14 yaş ve altındaydı. Ortalama yatış süreleri $2,48 \pm 0,76$ gündü. Sekiz olguya ortalama $2,28 \pm 1,58$ gün yapay solunum uygulanmıştır. Olgulardan bir tanesi yatışının üçüncü gününde kaybedilirken, 65 olgu şifayla taburcu edilmiştir. Mantar ve metil alkol intoksikasyonu olan 2 olguya hemodiyafiltrasyon uygulanmıştır. İntoksikasyonlar 3 yıl içinde yoğun bakım ünitemizde yatan hastaların \%15'ini oluşturmaktadır. Intihar amacıyla \%45 oranında antidepresan kullanımış ve antidepresan olarak en sık (\%63) amitriptilin seçilmiştir.

Sonuç: Olguların büyük kısmının genç ve sağlıklı olması, toksik doza ulaşmayan ilaç alımı, şuurlarının açık, solunumlarının yeterli olması prognozun iyi, mortalitenin düşük olmasına sebep olmaktadır. Zamanında yapılan doğru müdahale kadar reçetesiz ulaşılabilen ve en büyük intoksikasyon grubunu oluşturan amitriptilinin de satışının kontrolünün gerektiği düşüncesindeyiz.

Anahtar kelimeler: Yoğun bakım, intoksikasyon, antidepresan kullanımı
\end{abstract}

\section{ABSTRACT:}

Retrospective analysis of intoxicated patients in our intensive care unit

objective: Intoxications occurs generally accidentally, due to suicide attempts or related to drug abuse. We aimed to analyze intoxicated patients admitted to our intensive care unit (ICU) during three years period.

Materials and methods: Between 2007 and 2009, 66 ICU patients treated due to intoxication were retrospectively analyzed considering demographic variables, active ingredient associated with intoxication, hospital stay and ventilation time.

Results: There were 43 women and 23 men. The mean age of cases was $24,92 \pm 10,26$ years and 11 of them were $\leq 14$ years old. The mean hospitalization time of cases was $2,48 \pm 0,76$ days. The mechanical ventilation was applied to 8 of cases with a mean mechanical ventilation time of $2,28 \pm 1,58$ days. One of the cases died on the $3^{\text {rd }}$ day of hospitalization and other 65 cases were uneventfully discharged. Hemodiafiltration was applied in two cases intoxicated due of whom one was intoxicated by fungi and the other was intoxicated with methyl alcohol.

Intoxication cases were $15 \%$ all subjects treated in ICU during three years period. In $45 \%$ of patients, an antidepressant medication was found to be associated with suicide attempts and amitriptyline (63\%) was the most commonly used.

Conclusion: Good prognosis and the low mortality rate were supposed to be related to young age and healthy condition of the patients in addition to low dosage of the medicine-below the toxic level- being conscious and adequate respiratory functions at fist admission. We concluded that both marketing control necessity of control over, sales of amitriptyline, which is presently available without prescription and in the major intoxication group, is as important as treatment on time.

Key words: Intensive care unit, intoxication, antidepressant use

Ş.E.E.A.H. Tıp Bülteni 2013;47(2):63-66
'Uzm. Dr., Bağcılar Eğitim ve Araştırma Hastanesi, Anestezi ve Reanimasyon Kliniği, İstanbul-Türkiye

${ }^{2} U z m$. Dr., ${ }^{3}$ Doç. Dr., Şişli Etfal Eğitim ve Araştırma Hastanesi, ìstanbul-Türkiye

Yazışma Adresi / Address reprint requests to: Uzm. Dr. Tolga Totoz, Bağcılar Eğitim ve Araştırma Hastanesi, Anestezi ve Reanimasyon Kliniği, Merkez Mahallesi Mimar Sinan Caddesi 6. Sokak, istanbul-Türkiye

Telefon / Phone: +90-212-440-4000

E-posta / E-mail:

tolgatotoz@hotmail.com

Geliş tarihi / Date of receipt: 23 Ağustos 2012 / August 23, 2012

Kabul tarihi / Date of acceptance: 5 Eylül 2012 / September 5, 2012 


\section{GíRiş}

Zehirlenmenin tarihi insanlık tarihi kadar eskidir. Zehirlenmeler çok eski çağlardan beri toplumları yakından ilgilendiren önemli sorunlardan biri olmuştur $(1,2)$. Zehirlenme bir canlı organizmanın herhangi bir ajanla karşılaşarak işlevlerinin bozulmasıdır. M.Ö. 400 yıllarında yazıldığı sanılan Ebers Papirüslerinde pek çok zehirle (Katran ağacı, akonit, Opium, Kurşun, Bakır) ilgili veriler bulunmaktadır (1). Daha sonra ilk zehirlenme terimi 1230 'lu yıllarda İngilizlerce tanımlanmıştır ve tarih boyunca önemli bir sağlık sorunu olmuştur $(3,4)$.

Tüm dünyada zehirlenme olguları, acil servise başvuran hastalar arasında önemli bir yer tutmaktadır. Ülkemizde acil servise başvuran zehirlenme olgu sayısı, tüm olguların \%0.46-1.57'sini oluşturduğu bilinmektedir. Zehirlenmeler etkene, hastaneye başvuru süresine bağlı olarak ciddi sonuçlar doğurabilmektedir (5-7).

Zehirlenmeler, intihar amaçlı ilaç ya da madde alınması, farkında olmadan yüksek dozda ilaç kullanılması, ya da istenmeyen ilaç reaksiyonları olarak ortaya çıkabilmektedir. İlaçlara bağlı zehirlenmelerde mortalite kısmen daha düşük iken, genellikle intihar amacıyla alınan pestisitlerde mortalite artmakta ve dünyada yılda 300.000 kişinin bu nedenle öldüğü tahmin edilmektedir (5). Ülkemizde yaklaşık 150.000 zehirlenme olayı olduğu tahmin edilmektedir (6). Acil servise başvuran bu hastalardan bir kısmı yoğun bakım tedavisi gerektirmektedir. Yoğun bakım üniteleri yataklarının \%5-30 kadarı zehirlenme olguları için kullanılmaktadır (7).

Zehirlenmeye yol açan etkenler coğrafi koşullara, yaşa, cinsiyete, ailenin eğitim düzeyine, yaşanılan bölgenin gelenek ve göreneklerine ve mevsimlere göre değişmektedir. Bu nedenle, her ülkenin kendi zehirlenme profilini belirlemesi, buna göre karşı karşıya kaldığı risk ve tehditlere göre gerekli önlemleri alması gerekmektedir (8).

Biz de yoğun bakım ünitemizde takip ettiğimiz intoksikasyon olgularının sıklığını ve profilini belirlemek için 3 yıllık yoğun bakım ünitesi verilerimizi geriye dönük inceledik.

\section{GEREÇ ve YÖNTEM}

01 Ocak 2007-31 Aralık 2009 tarihleri arasında Şişli Etfal Anesteziyoloji ve Reanimasyon Kliniği yoğun bakım ünitesinde takip ve tedavisini yaptı̆̆ımız 66 (23 Erkek 43 kadın) hastanın kayıt ve dosyaları geriye dönük olarak incelenerek, hastaların yaş, cinsiyet, zehirlenme amacıyla aldığı ilaç, maruz kalma şekli, klinikte yattığı gün sayısı, mekanik ventilasyon desteği aldığı gün sayısı ve mortalite açısından değerlendirildi.

İstatistiksel analiz, SPSS 10.0 programında yapıldı. Veriler sayı $(\mathrm{n})$ veya ortalama \pm standart sapma (SS) olarak sunuldu.

\section{BULGULAR}

Hastaların demografik verileri ve yoğun bakımda yatış süresi ile hastaların hastaneden çıkış durumları Tablo 1'de gösterilmiştir.

64 olgu hastaneden sağlıklı bir şekilde taburcu

Tablo 1: Demografik veriler

Kadın-Erkek oranı

Olguların yaş ortalaması

Olguların ortalama hastanede yatış süresi

Tablo 2: Glaskow koma skalası (yoğun bakıma gelişte)

\begin{tabular}{cc}
\hline Glaskow Koma Skalası & Olgu Sayısı \\
\hline 3 & 2 \\
5 & 5 \\
8 & 1 \\
12 & 6 \\
15 & 52
\end{tabular}

Tablo 3: Intoksikasyon etkenleri

\begin{tabular}{|c|c|c|c|c|c|}
\hline Antidepresan & 30 & Karbamazepin & 2 & Metil alkol & 1 \\
\hline Parasetamol & 8 & Fenitoin & 2 & Morfin & 1 \\
\hline Risperidon & 5 & Oksibutinin & 1 & ASA & 1 \\
\hline Multi ilaç & 5 & Diltiazem & 1 & Trazadon & 1 \\
\hline Klonezepam & 2 & Kolşisin & 1 & Teofilin & 1 \\
\hline Organik fosfat & 2 & Mantor & 1 & Çatapat & 1 \\
\hline
\end{tabular}


Tablo 4: Antidepresan sınıflaması

\begin{tabular}{llll}
\hline Amitriptilin & 19 & Vellafaksin & 2 \\
Sertralin & 3 & Klomipramin & 2 \\
Alprozolam & 3 & Mirtezapin & 1
\end{tabular}

edilmiştir. Bir olgu madde bağımlılığı sebebi ile diğer bir kliniğe sevk edilmiştir. Bir olgu mantar intoksikasyonuna bağlı çoklu organ yetmezliği nedeniyle yatışının üçüncü günü ölmüştür.Sekiz olguya yapay solunum uygulanmıştır. Ortalama yapay solunum süresi 2,28 $\pm 1,58$ gündür.

Mantar ve metil alkol intoksikasyonu olan iki olguya hemodiyafiltrasyon uygulanmıştır.

İntoksikasyonlar 3 yıl içinde yoğun bakım ünitemizde yatan 442 olgunun \%15'ini oluşturmaktadır. Olguların \%65'i genç bayanlardır. İntihar amacıyla $\% 45$ oranında antidepresan kullanılmış ve antidepresan olarak \%63 oranıyla da amitriptilin seçilmiştir.

\section{TARTIŞMA}

Acil servise başvurularda zehirlenme olguları en sık nedenlerden biri olmasına karşın epidemiyolojik özellikler ülkeden ülkeye, hatta aynı ülke içinde farkI । bölgelere göre değişiklik göstermektedir. Acil servise başvuruda Çin'de \%3, İngiltere'de \%1 oranında zehirlenmeye rastlanmaktadır. Türkiye de ise $\% 0.5$ 1.57 oranlarında zehirlenme bildirilmiştir (9-12).

Birçok zehirlenmede erken dönemde yapılan sağaltım girişimleriyle henüz zehirin toksik etki oluşturmadan vücut dışına atılması, adsorbe edilmesi veya antidot kullanımıyla zararlı etkilerinin ortaya çıkmaması sağlanabilir. Acil serviste çalışanların toksikoloji bilgilerinin güncellenmesi, toksikolojik tanı olanaklarının sağlanması, monitörizasyon ve yoğun bakım imkanının olması, antidot bulundurulması acil servislerde zehirlenmelerin tanı ve tedavisinin uygun şekilde yapılabilmesi için gerekmektedir (10).

Zehirlenmeler, önemli bir sağlık ve sosyoekonomik problemdir. Dünyada oranı gittikçe artmaktadır. Klinik olarak akut zehirlenmeden şüphelenildiğinde morbidite ve mortalite oranı yüksek olduğundan erken tanı ve tedavi yapılmalıdır (13). Zehirlenmelerin mortalite oranları \%0.3-27 arasında bildirilmektedir. Gaziantep Üniversitesindeki mortalite oranı \%2.8 olarak bildirilmiştir (14). Biz mortalite oranını
\%1 olarak saptadık.

Amerikan zehir kontrol merkezleri 1983'den beri Zehirlenme İzlem Sistemi oluşturmuşlardır. Bu merkezin 2000 yılı raporunda 63 merkez verilerine göre toplam 2,2 milyon civarındaki olgunun üçte biri erişkin yaş grubunda olup bunların \%71'i kaza sonucu zehirlenmekte ve olguların \%92'si de tek ajana maruz kalmaktadırlar (15). Serinken ve Yanturalının çalışmasında 257 akut zehirlenme olgusunun \%71'i kadın, \%88.7'si 17-40 yaş grubunda olduğu saptanmıştır (16).Bizim hastanemizdeki olguların yaş dağılımına bakıldığında \% 83'ünün erişkin yaş grupta olduğu, yani 14 yaş üzeri olduğu ve bunların \%65'ini kadın olguların oluşturduğu tespit edilmiştir. Ayrıca tek ajana maruz kalma oranımız \%92'dir. Zehirlenme olgularının çoğunda zehirlenme etkenlerinin vücuda giriş yolu olarak oral yol ön plandadır $(17,18)$.

Zehirlenmeler ile ilgili bir derlemede, gelişmiş ülkelerde intihar amacıyla en çok yüksek doz ilaç (analjezikler, antidepresanlar) alındığını ve mortalitenin bu olgularda \%0.5 civarında olduğu. Bu olguların büyük bölümünün genç ve sağlıklı olması konunun önemini daha da artırmaktadır (5). Olgularımızda birinci sıklıkla alınan ilaç bir antidepresan olan amitriptilindi. Depresif hastalarda intihar girişimi yüksektir ve genellikle depresyon tedavisinde kullandıkları ilaçlarla intihar girişiminde bulunmaktadırlar. Bu konuda yapılan araştırmalar intihar girişimlerinin $\% 50$ 'i oluşturan olguların daha önceden psikiyatrik sorunları olan hastalar olduğunu göstermiştir $(19,20)$.

Hastanemiz bünyesinde Anestezi ve Reanimasyon Kliniği olarak Ağustos 2007-2008 tarihleri arasında yaptığımız konsultasyonların \%25'ini intoksikasyon olguları oluşturmuş ve 31 olgu yoğun bakım ünitemize alınabilmiştir. Aynı yıl yoğun bakım ünitemize kabul edilen olguların \%18'ini oluşturmaktadır (21).

Sonuç olarak; zehirlenmeye neden olan maddelerin çok azına karşı antidot mevcuttur. Ancak bu maddelere karşı antidot kullanımının hayat kurtarıcı olması nedeniyle çok değerli olan bu ilaçların bulundurulması, temini ve kullanımı konusunda herkesin üzerine düşeni yapması gerekmektedir. Olguların büyük kısmının genç ve sağlıklı olması, toksik doza ulaşmayan ilaç alımı, şuurlarının açık, solunumlarının yeterli olması iyi prognoz ve düşük mortalite 
oranlarının sağlanmasında katkıda bulunan nedenler arasındadır. Olgularımızın \% 16'lık grubunu 14 yaş ve altı çocuklar oluşturmakta ve bunların bir kısmının intihar amaçlı olması da düşündürücüdür. Zamanın- da yapılan doğru müdahale kadar reçetesiz ulaşılabilen ve en büyük intoksikasyon grubunu oluşturan amitriptilinin de satışının kontrolünün gerektiği düşüncesindeyiz.

\section{KAYNAKLAR}

1. Demirkıran O Zehirlenmeler. İstanbul Üniversitesi Cerrahpaşa Tıp Fakültesi Tıp Eğitimi etkinlikleri 2002; 29: 109-139.

2. Chirasirisap K, Ussanawarong S, Tassaneeyakul W, et al. A study of major cause and types of poisoning in Khonkaen, Thailand. Veterinary and Human Toxicology 1992; 34: 489-492.

3. Pekdemir M, Kavalcı C, Durukan $P$ ve ark. Acil servisimize başvuran zehirlenme olgularının değerlendirilmesi. Acil Tıp Dergisi 2002; 2: 36-40.

4. Wax PM History. In: Goldfrank LR, Flomenbaum NE. Toxicologic Emergencies (Ed 6th) New York, McGraw-Hill 1998; pp. 1-14.

5. Gunnell D, Eddleston M. Suicide by intentional ingestion of pesticides: a continuing tragedy in developing countries. Int J Epidemiol, 2003; 32: 902-909.

6. Pekdemir M, Yıldız M, Durukan P, Kavalcı C. Acil servise başvuran erişkin zehirlenme olgularının prospektif olarak incelenmesi Toksikoloji Dergisi 2004; 2: 41-48.

7. Henderson A, Wright M, Pond SM. Experience with acute overdose patients admitted to an intensive unit over six years. Med J Aust, 1993; 158: 28-30.

8. Özdemir R, Bayrakcı B. Zehirlenmeler ve Hacettepe Deneyimi. Katkı Ped Derg 2009; 31: 47-87.

9. Kurt $i$, Güner Erpek A, Nil Kurt $M$ ve ark. Adnan Menderes Üniversitesinde izlenen zehirlenme olguları. Adnan Menderes Üniversitesi Tıp Fakültesi Dergisi 2004; 5: 37-40.

10. McGrath J.Asurvey of deliberate self-poisoning. Medical Journal of Australia 1989; 150: 317-324.

11. Liu Y, Wolf $L R$, Zhu W. Epidemiology of adult poisoning at China Medical University. Clinical Toxicology 1997; 35: 175-180.

12. Thomas SHL, Bevan L, Bhattacharyya $S$, et al. Presentation of poisoned patients to accident and emergency departments in the North of England. Human\&Experimantal Toxicology 1996; 15: 466-470.
13. Soori H. Developmental risk factors for unintentional childhood poisoning. Saudi Medical Journal 2001; 22: 227-230.

14. Göksu S, Yıldırım C, Koçoğlu H ve ark. Characteristics of acute adult poisoning in Gaziantep, Turkey. Journal of ToxicologyClinical Toxicoloy 2002; 40: 833-837.

15. Mokhlesi B, Leiken JB, Murray P et al. Adult toxicology in critical care; Part I: general approach to the intoxicated patient. Clinics in Chest Medicine 2003; 123: 577-592.

16. Serinken M, Yanturalı S Acil serviste intihar amaçlı zehirlenmelerin geriye dönük analizi. Toksikoloji 2003; 1: 15-19.

17. Öner N, Inan $M$, Vatansever $\ddot{U}$ ve ark. Trakya bölgesinde çocuklarda görülen zehirlenmeler. Türk Pediatri Arşivi 2004; 39 : 25-30.

18. Koturoğlu G, Kurugöl Z, Yiğit M, Solak I. Ege Üniversitesi Tıp Fakültesi Çocuk Acil Ünitesine zehirlenme nedeniyle başvuran olguların değerlendirilmesi. Ege Pediatri Bülteni 2005; 3: 161 165.

19. Kaygusuz K, Gürsoy S, Kılıçcıoğlu F, Özdemirkol i, Mimaroğlu C. Cumhuriyet üniversitesi tıp fakültesi hastanesi yoğun bakım ünitesinde 1998-2004 yılları arasında akut ilaçzehirlenmesi tanısı ile takip edilen olguların geriye dönük analizi. CÜ Tıp Fakültesi Dergisi, 2004; 26: 161-165.

20. Staikowsky F, Uzan D, Grillon N, et al. Voluntary drug poisoning cases admitted to an emergency care unit. Presse Med, 1995; 24: 1296-1300.

21. Işıl C, Türk Ş, Sayın P, Çınar S, Oba S. Hastanemiz yoğun bakım ünitesinden acil konsültasyon istemlerinin değerlendirilmesi Ş.E.E.A.H. Tıp Bülteni 2012;46(2):49-52. 